\title{
Revisitando mitologias pelas lentes dialógicas
}

Beth Brait $^{\star}$

\section{Resumo}

Em Mitologias, obra publicada na França em 1957 e traduzida para o português em 1972, Roland Barthes reuniu textos cujo objetivo era realizar uma crítica ideológica da cultura dita de massa e, ao mesmo tempo, realizar uma desmontagem semiológica dessa linguagem. Embora tivesse predominantemente o visual e o verbo-visual como objeto de análise (fotografia, publicidade, imprensa, etc.), os ensaios não traziam ilustrações. Meio século depois, Jacqueline Guittard retoma esse trabalho, ilustrando-o com imagens da época. O resultado é a edição Mythologies ilustrées, com os textos integrais e mais de 120 ilustrações que possibilitam ver, hoje, imagens que serviram para que o autor demonstrasse, com perspicácia e ironia, o funcionamento mitológico de temas presentes na sociedade naquele momento. Neste artigo, o objetivo é discutir a possibilidade de leitura da verbo-visualidade, a partir da teoria dialógica do discurso proposta por Bakhtin e o Círculo, tomando como objeto um dos ensaios de Mythologies ilustrées: detergentes e saponáceos. $\mathrm{Da}$ perspectiva do verbal, têm-se a análise de Barthes. Da perspectiva visual, outra autoria junta-se para apresentar imagens, não propriamente extraídas dos baús do autor, mas recuperadas dos objetos de suas análises, os quais circulavam em seu tempo. Este artigo pretende discutir alguns sentidos e efeitos de sentido possibilitados pela articulação solidária verbal/visual, escrita/imagem nessa dupla autoria. Tratando-se do trabalho de leitura da sociedade e de suas crenças a partir de uma peça publicitária, também se pretende observar se/e quais os mitos aí detectados, pela desmontagem semiológica, resistem à leitura contemporânea ou se perdem no tempo.

Palavras-chave: Mitologias contemporâneas. Roland Barthes. Publicidade. Verbo-visualidade. Análise dialógica do discurso.

Professora Livre-Docente, Programa de Estudos Pós-graduados em Linguística Aplicada e Estudos da Linguagem/LAEL e do Programa de Estudos Pós-graduados em Literatura e Crítica Literária/LCL da Pontifícia Universidade Católica de São Paulo, São Paulo; e-mail: bbrait@uol.com.br.

Data de submissão: mar. 2014 - Data de aceite: abr. 2014 http://dx.doi.org/10.5335/rdes.v10i1.4094 


\section{Introdução}

Alguém poderia perguntar qual a utilidade, hoje, de retomar análises feitas nos anos de 1950/60, que tinham como fundamentação teórica a semiologia, ou seja, uma perspectiva teórica de análise inspirada em Ferdinand de Saussure (1857-1913), para quem a Linguística era apenas uma parte da ciência da linguagem, incluída numa ciência maior, denominada Semiologia. Essa sim seria capaz de abranger não apenas os sistemas de signos verbais, tarefa da Linguística, mas qualquer outro: música, pintura, cinema, fotografia, teatro, etc. A resposta poderia assumir várias formas e duas serão destacadas a seguir.

A primeira poderia ser a que diz respeito à concepção de pesquisa nas Ciências Humanas, universo do conhecimento no qual sempre se pode voltar ao passado, a alguns pontos de partida, não para retomá-los ou incensá-los, pura e simplesmente, mas para conhecer ou reconhecer, em sua discursividade teórica inaugural, elementos que permitam iluminar aspectos atuais da pesquisa sobre o homem, sobre seus discursos. Mais precisamente, o enfoque no verdadeiro objeto das Ciências Humanas, ou seja, os sujeitos sociais, culturais, as falas por meio das quais esses sujeitos se expressam, se dizem, instaurando discursos de toda ordem, submetendo-se a eles ou subvertendo-os. Nesse sentido, ninguém ignora o velho Aristóteles no momento de estudar e recuperar, por exemplo, o conceito de ethos. E nem por isso, simplesmente repete e mobiliza a concepção aristotélica. Ao contrário, reorganiza a discursividade a respeito dessa noção, tratando-a sob um novo enfoque e inserindo a nova face na tradição inesgotável de mobilização desse conceito. $\mathrm{O}$ mesmo movimento de pesquisa pode ser observado nos mais avançados estudos enunciativos, e até mesmo discursivos, quando a força e a pertinência dos conceitos de pessoa, lugar e tempo são mobilizadas para conhecer textos, discursos, sentidos e efeitos de sentido. Seria impossível descartar ou ignorar a maneira como Émile Benveniste (19021976) pensou a dimensão intersubjetiva da linguagem, a passagem da língua para o discurso, a partir dessas três categorias enunciativas, instauradas como diferencial de sua discursividade teórica inaugural sobre a enunciação. Trata-se, portanto, de um retorno a algum ponto de partida, a algum gesto inaugural, para aportar em uma nova ou complementar reflexão acerca da linguagem.

Outra resposta possível à importância da releitura das Mitologias de Barthes seria a que diz respeito ao fato de que, nesses estudos, o autor não estava apenas sob a influência da Semiologia, ciência que segundo ele, no momento em que escreveu essa obra, ainda não havia se constituída, e das estruturas do mito como os o pensou, por exemplo, Claude Lévi-Strauss (1908-2009). Isto é, não aplicou uma fundamentação teórica $\mathrm{e}$ metodológica advinda da linguística e da 
antropologia estrutural para desvendar sentidos e efeitos de sentido de vários sistemas de signos. Em sua genialidade, estava interessado nos mitos contemporâneos veiculados, por exemplo, pela mídia, pela publicidade, por diferentes formatos assumidos pelas falas (termo hoje correntemente substituído por discursos) que expõem o homem situado socialmente, assim como pelas relações de poder que estavam em jogo, pelo imaginário coletivo que transitava pelo que se denominava, naquele momento, meios de comunicação de massa, instaurando e afetando crenças, maneira de ser e agir, concepções de mundo, valores. Em última instância, para usar uma palavra utilizada por Barthes, a partir desse instrumental teórico e metodológico tocar, desvendar, expor camadas da ideologia dominante, presente na linguagem cotidiana em suas diferentes configurações e na mitologia ali criada e alimentada.

É nesse sentido que o trabalho interessa, especialmente em sua versão verbo-visual. Mesmo sendo aparentemente datado do ponto de vista teórico e também social (as análises abrangem mais diretamente a sociedade francesa), ele se apresenta como tentativa bem sucedida de leitura, pelas vias da linguagem trabalhada pelos meios de comunicação, do homem situado socialmente e das formas assumidas pelas mitologias que o envolviam. Para se ter ideia, há um artigo, intitulado "Cozinha ornamental" que começa da seguinte maneira:
A revista Elle (verdadeiro tesouro mitológico) apresenta-nos quase todas as semanas uma bela fotografia a cores de um prato elaborado [...] (BARTHES, 1972, p. 77).

O destaque vai para a expressão "verdadeiro tesouro mitológico", qualificando um exemplar da imprensa dedicada à mulher. $\mathrm{Na}$ distância dos 60 anos que separam essas análises da atualidade, é possível perguntar se restou algo dessa discursividade inaugural que permita, pela via dialógica da leitura da verbo-visualidade, dizer algo do homem contemporâneo, das mitologias que o envolvem, da ideologia formatada pela publicidade. De que formas a sociedade atual, e sua publicidade de produtos semelhantes aos que foram analisados por Barthes, lança mão para realizar, construir e veicular mitos? Essa é a razão de tomar essa obra, que mesmo pertencendo a Barthes, agora aparece como um escrito a quatro mãos: os textos verbais, os ensaios, são barthesianos e estão integralmente apresentados na nova edição; as ilustrações, entretanto, advêm de uma pesquisa recente, assumida pela autora Jacqueline Guittard (professora e pesquisadora da Universidade Picardie Jules Verne, Amiens/França), que além das ilustrações inclui na obra, como último ensaio, o seu: Illustrer les Mythologies [Ilustrar as Mitologias], momento em que explica os processos que envolveram a escolha das ilustrações e a elaboração da nova edição.

Para tentar responder às perguntas que levaram a retomadas das Mitologias barthesianas, este artigo terá como 
corpus principal a crônica Saponáceos e detergentes (BARTHES, 2010, p. 3637), remetendo sempre que necessário a alguns outros textos publicitários. Para efeito de traduções, o ponto de referência será a edição brasileira (BARTHES, 1972). Antes de entrar diretamente na discussão do texto e das imagens que o completam (e reinstauram), serão retomados alguns aspectos que caracterizam a possibilidade de leitura da verbo-visualidade, a partir das concepções teóricas e metodológicas advindas do conjunto da obra de Bakhtin e do Círculo.

\section{Na mira da inesgotável produção de sentidos}

Na edição de 2010 - um verdadeiro livro de arte, pelo tamanho ( $25 \mathrm{~cm}$ por $34 \mathrm{~cm}$ ), pela qualidade das surpreendentes ilustrações e, também, pelo ensaio intitulado Illustrer les Mytologies [Ilustrar as Mitologias], assinado pela organizadora Jacqueline Guittart -, são detalhados os objetivos da iconografia e da edição verbo-visual:

[...] propor ao leitor o documento autêntico, ou seja, aquele que Roland Barthes tinha sob seus olhos ou o que tinha na lembrança, e, se ele nada mais tivesse na memória, se ater ao menos ao que estivesse à disposição no momento em que redigia as crônicas (GUITTARD, 2010, p. 249). ${ }^{1}$

A autora declara ainda que:

Não são ilustrações barthesianas propriamente ditas que se encontrarão lendo as crônicas, mas mais simplesmente as de seu tempo, escolhidas o mais próximo possível da escritura mitológica e dos acontecimentos (GUITTARD, p. 252). ${ }^{2}$
Assim, para trabalhar a relação verbo-visual que passa a existir entre o texto de Barthes, Saponides et détergents [Saponáceos e detergentes], que está integramente apresentado por Guittard (2010, p. 36) e a ilustração por ela escolhida (2010, p. 37), alguns pressupostos teóricos e metodológicos serão resumidos a seguir, iniciando-se por dois considerados centrais para a análise de qualquer plano de expressão assumido por uma comunicação discursiva e suas formas de produção de sentido: texto e discurso. Não é demais lembrar que há variados conceitos de texto, assim como de discurso, e que eles diferem de acordo com as diferentes teorias que os formulam, caso da filologia, da semiologia, das semióticas, das análises do discurso, da linguística textual, da teoria da enunciação, da teoria literária, dentre outras, implicando, cada uma delas, diversas tendências e, consequentemente, diferenciadas concepções dessas noções. Neste artigo, tanto o conceito de texto como o de discurso serão mobilizados a partir da perspectiva bakhtiniana, estabelecida por Bakhtin e pelos demais membros do Círculo. ${ }^{3}$

Para o conceito de texto, é possível tomar como base, dentre vários outros estudos do Círculo, de um lado, $O$ problema do texto na linguística, na filologia e em outras ciências humanas (BAKHTIN, 2003, p. 307-335) e, em diálogo com ele, Estudo das ideologias e filosofia da linguagem, capítulo primeiro da parte inicial da obra Marxismo e filosofia 
da linguagem: problemas fundamentais do método sociológico (BAKHTIN/ VOLOCHINOV, 1997, p. 31-38). Se no primeiro a discussão está centrada na ideia de texto como realidade das Ciências Humanas, aí incluídos os estudos do discurso, no segundo é possível surpreender o momento em que se estabelece a passagem, mas não o apagamento ou exclusão, do signo como constitutivo de um sistema e de suas leis combinatórias, apontando para uma nova dimensão: a realização desse signo numa situação concreta, histórica, possibilitada pela interação, pelo gesto de um sujeito que fala (escreve, pinta, compõe uma canção, desenha uma história em quadrinhos, etc.) e se dirige a outro sujeito. Essa atualização do signo em forma de enunciado, de linguagem em uso, confere ao signo a condição de signo ideológico. Não se trata mais do signo assumido unicamente como elemento de um sistema, mas como dimensão semiótica carregada de valores, dimensão veiculadora de ideologia, de discursos sociais, culturais, situados historicamente. A articulação entre esses dois estudos possibilita, portanto, uma compreensão de texto própria da perspectiva dialógica, da análise dialógica do discurso $(\mathrm{ADD})^{4}$ : conjunto coerente de signos ideológicos. Essa concepção, na qual se fundará a leitura apresentada neste artigo, considera as duas sequências - a verbal, representada pelo escrito de Barthes, e a visual, representada pela ilustração -, como dois textos que, ao se avizinharem pela realidade de um novo projeto gráfico, de um novo projeto de dizer, constituem um novo plano de expressão - verbo-visual ${ }^{5}$ - e, por isso, desencadeiam novas formas de produção de sentido. Os dois textos teóricos selecionados, por sua vez, serão considerados não em todas as suas implicações, mas a partir de aspectos destacado a seguir.

Da reflexão desenvolvida por Bakhtin em $O$ problema do texto na linguística, na filologia e em outras ciências humanas e que envolve inúmeros e importantes aspectos retomados e desenvolvidos ao longo do estudo, é possível destacar, para os interesses deste artigo, a ideia de que o texto é o ponto de partida e ponto de chegada para o pesquisador das Ciências Humanas. Dentre os diversos momentos em que $o$ autor discute essa especificidade do texto, essa dimensão por meio da qual o pesquisador tem acesso ao homem, formulando perguntas a respeito desse verdadeiro objeto falante das Ciências Humanas, há um trecho bastante significativo, que está assim formulado:

O texto é o dado (realidade) primário e o ponto de partida de qualquer disciplina nas ciências humanas. Um conglomerado de conhecimentos e métodos heterogêneos chamado filologia, linguística, estudos literários, metaciência, etc. Partindo do texto, eles perambulam em direções diferentes, agarram pedaços heterogêneos da natureza, da vida social, do psiquismo, da história, e os unificam por vínculos ora causais, ora de sentido, misturam constatações com juízos de valor. Da alusão ao objeto real é necessário passar por uma delimitação precisa dos objetos de investigação científica... O objeto real é o homem social (inserido na sociedade), que fala e exprime a si mesmo por outros meios. Pode-se encontrar para 
ele e para a sua vida (o seu trabalho, a sua luta, etc.) algum outro enfoque além daquele que passa pelos textos de signos criados ou a serem criados por ele? [...] quando estudamos o homem, procuramos e encontramos signos por toda parte e nos empenhamos a interpretar o seu significado (BAKHTIN, 2003, p. 319).

Para compreender essa realidade sígnica com a qual se defronta o pesquisador das Ciências Humanas e por meio da qual é possível dialogar com o homem e dele conhecer alguma coisa, há, dentre várias outras definições, a que é apresentada logo no início do trabalho e que relaciona texto/signo: "[...] texto no sentido amplo como qualquer conjunto coerente de signos" (BAKHTIN, 2003, p. 307). Considerando essa definição e articulando-a com a maneira como signo ideológico está definido em Marxismo e filosofia da linguagem - "tudo que é ideológico é um signo. Sem signos não existe ideologia" (BAKHTIN/VOLOCHINOV, 1997, p. 31) -, chega-se à concepção semiótico-ideológica de texto assumida neste artigo e já anunciada acima: texto como conjunto coerente de signos ideológicos.

Há várias consequências a serem assumidas, a partir do momento em que essa é a concepção de texto que possibilitará uma leitura da comunicação discursiva assumida como corpus verbo-visual.

A primeira diz respeito ao fato de que texto é assumido como qualquer conjunto coerente de signos ideológicos, passível de ser entendido, portanto, como verbal, visual e/ou verbo-visual e que sua abordagem, sua leitura, não poderá desconsiderar as especificidades de seu plano de expressão para avaliar as formas de produção de sentido e de efeitos de sentido aí estabelecidas. Essa consequência pode ser reafirmada no fato de que a perspectiva bakhtiniana não se propõe a ser uma teoria do texto, embora o tome como única realidade do pesquisador. Ela se apresenta, no conjunto compreendido pelos trabalhos de Bakhtin e do Círculo, como teoria da linguagem e, mais especificamente, como se verá na sequência, como uma teoria/ análise do discurso.

Ainda que o texto seja entendido como a única realidade ao alcance do pesquisador das Ciências Humanas, há, por parte de Bakhtin, certa desconfiança em relação ao termo, que poderia ser entendido como uma unidade de sentido autônoma. Por essa razão, o autor reforça a ideia de texto não como unidade autônoma, mas, ao contrário, necessariamente ligada a uma rede de outros textos, enunciados, discursos. Essa unidade de sentidos, quer seja denominada texto ou enuncia$d o$, pressupõe enunciados que a antecedem, a quem ela responde, e enunciados que a sucedem, que a ela respondem ou responderão, abrangendo um contexto mais amplo que a situação de sua produção. Por essa razão, nenhum enunciado pode ser o primeiro ou o último. Ele é, de fato, um dos elos de uma extensa cadeia de comunicação discursiva, confirmando a perspectiva dialógica de produção de sentidos, pressupondo a interação que, muito longe de ser um enfrentamento discursivo harmonioso, diz respeito a 
uma rede de respostas assumidas por ponto de vistas, por sujeitos situados.

Assumir essa concepção de texto significa reconhecer que a teoria dialógica não é uma teoria do texto. É, antes, uma teoria do discurso, que trabalha com enunciados situados histórica e socialmente, sempre em tensão, tendo como categoria fundante as relações dialógicas. Essas relações não estão prontas, acabadas nos textos em si, nos enunciados em si, mas dependem do ponto de vista de um sujeito, sendo, por isso, de diferentes tipos, incluindo uma gama que vai das mais harmônicas às abertamente polêmicas. Para apreender essas relações, o pesquisador, o analista, considera tanto a materialidade linguística/visual ou verbo-visual, aquilo que pode ser considerado interno ao texto/ enunciado, como a exterioridade, o extralinguístico incluído na complexidade das relações dialógicas aí estabelecidas e que apontam para fora do enunciado, que sinalizam discursos que o constroem e/ou são por ele produzidos, veiculados, passíveis de serem reconhecidos.

Relações dialógicas, portanto, implicam discurso. Sabe-se que discurso é um conceito que, como texto, ou qualquer outra categoria de análise, assume diferentes acepções em diferentes teorias. $\mathrm{Na}$ teoria dialógica, discurso é entendido como uma rede de relações dialógicas. $\mathrm{O}$ discurso, que passa a ser indicado pela expressão relações dialógicas, foi definido por Bakhtin como objeto da metalinguística ou translinguística, conforme explicitado em Problemas da poética de Dostoiéviski (BAKHTIN, 2008). Discurso, evidentemente, sempre entendido como social, histórico, cultural, etc., entretecido por relações dialógicas entre signos ideológicos, entre palavras, entre textos. Essa concepção de discurso esclarece um gesto teórico-metodológico, ou seja, uma maneira de conceber e abordar a linguagem que hoje se define como perspectiva dialógica. Assim, há outro conceito que deve ser associado aos demais na busca da sintaxe, da gramática, das formas de produção de sentidos de um plano de expressão verbo-visual, objeto deste estudo. Trata-se de esfera ideológica.

Reconhecendo o texto/enunciado e os discursos que o constroem, que nele circulam, que dele podem ser depreendidos, como unidade de sentidos, é possível afirmar que essa dimensão significativa está articulada por um projeto discursivo, um projeto de dizer. Esse projeto de dizer não é autônomo, livre, solto. Ele ocorre dentro de uma esfera_ideológica, um campo ideológico, de acordo com coerções aí existentes em termos de condições de produção, circulação e recepção. Essa esfera, essa dimensão em que se dá a comunicação discursiva, está definida, dentre outros lugares dos textos de Bakhtin e do Círculo, de maneira bastante esclarecedora em Marxismo $e$ filosofia da linguagem:

No domínio dos signos, isto é, na esfera ideológica, existem diferenças profundas, pois este domínio é, ao mesmo tempo, o da representação, do símbolo religioso, da fórmula científica e da forma jurídica, etc. Cada 
campo de criatividade ideológica tem seu próprio modo de orientação para a realidade e refrata a realidade à sua própria maneira. Cada campo dispõe de sua própria função no conjunto da vida social. É seu caráter semiótico que coloca todos os fenômenos ideológicos sob a mesma definição geral (BAKHTIN/ VOLOSHINOV, 1997, p. 33).

Portanto, a esfera de circulação de um texto ou de um conjunto de textos implica suas formas de produção e suas formas de recepção. Isso significa que a mudança de um texto de uma esfera a outra esfera, altera, modifica, ou subverte as relações implicadas nos discursos que constituem esse texto ou um conjunto de textos, como se verá no ensaio analisado. Inicialmente os textos de Barthes circularam na imprensa francesa. Depois foram organizados em livro. E, por último, reaparecem em nova edição, complementados por ilustrações advindas não de arquivo do autor, mas de pesquisas assinadas por outra autoria. As mudanças implicam, necessariamente, novas formas de produção de sentidos, comopoderemos observar. Tendo esses fundamentos teóricos e metodológicos como ponto de partida, a verbo-visualidade instaurada pela obra Mythologies Ilustrées, particularmente no que diz respeito ao estudo intitulado em português Saponáceos e detergentes, a leitura pretendida por este artigo pode ser entendida como diálogo entre mitos do passado e presente.

\section{Ver e ler: direções a seguir}

A novidade da edição de Mitologias (2010) é a ilustração, como indicado. Por isso, a tendência do leitor, certamente um conhecedor dos textos constitutivos da obra, é folhear cuidadosa e pacientemente o exemplar, fruindo a visualidade sugerida, imaginada, idealizada no momento da leitura do conjunto dos ensaios verbais. Ao chegar às páginas 36 e 37 do volume, o leitor, já tomado pela verbo-visualidade dos ensaios anteriores, ricamente ilustrados por magníficas fotos de época e/ou recortes de jornal, depara-se com mais uma sequência harmoniosamente organizada. A página da esquerda (36) está ocupada pelo o texto verbal, o ensaio já conhecido: título no alto, à direita, em destaque, Saponides et detérgents, apresentado em duas linhas; o corpo do texto, ocupando duas colunas distribuídas na vertical e separadas por um traço. Entretanto, apesar do interesse pela releitura, é a página da direita que atrai, de imediato, o olhar desse leitor transformado em espectador, desse quase voyeuer, desejoso de confirmar se as imagens que formou a partir da leitura do texto verbal, feita certamente num passado distante... mas ainda presente na memória, se confirmam.

O conjunto, simetricamente organizado, é composto por três sequências enquadradas, que, embora separadas por espaços-molduras, constituem um conjunto, um único projeto gráfico. Em branco e preto e tendo como motivo a publicidade de duas marcas de sabão em 
pó, apresentadas em duas sequências menores, formadas por fotos posicionadas verticalmente à esquerda, e uma terceira, maior, à direita, formada a partir de desenhos, ocupando o restante da página. A articulação das três oferece um plano de expressão emoldurado por um retângulo, também posicionado verti- calmente. Abaixo, obedecendo por assim dizer a distribuição das ilustrações, aparecem as fontes das publicidades: as da esquerda foram publicadas pela revista Elle, ํㅜ. 479, de 14 de fevereiro de 1955 , e $n^{\circ} .461$ de outubro de 1954, respectivamente. A fonte da maior é o jornal $L e$ Figaro de 6 de setembro de 1954.

Figura 1 - Sequência 1
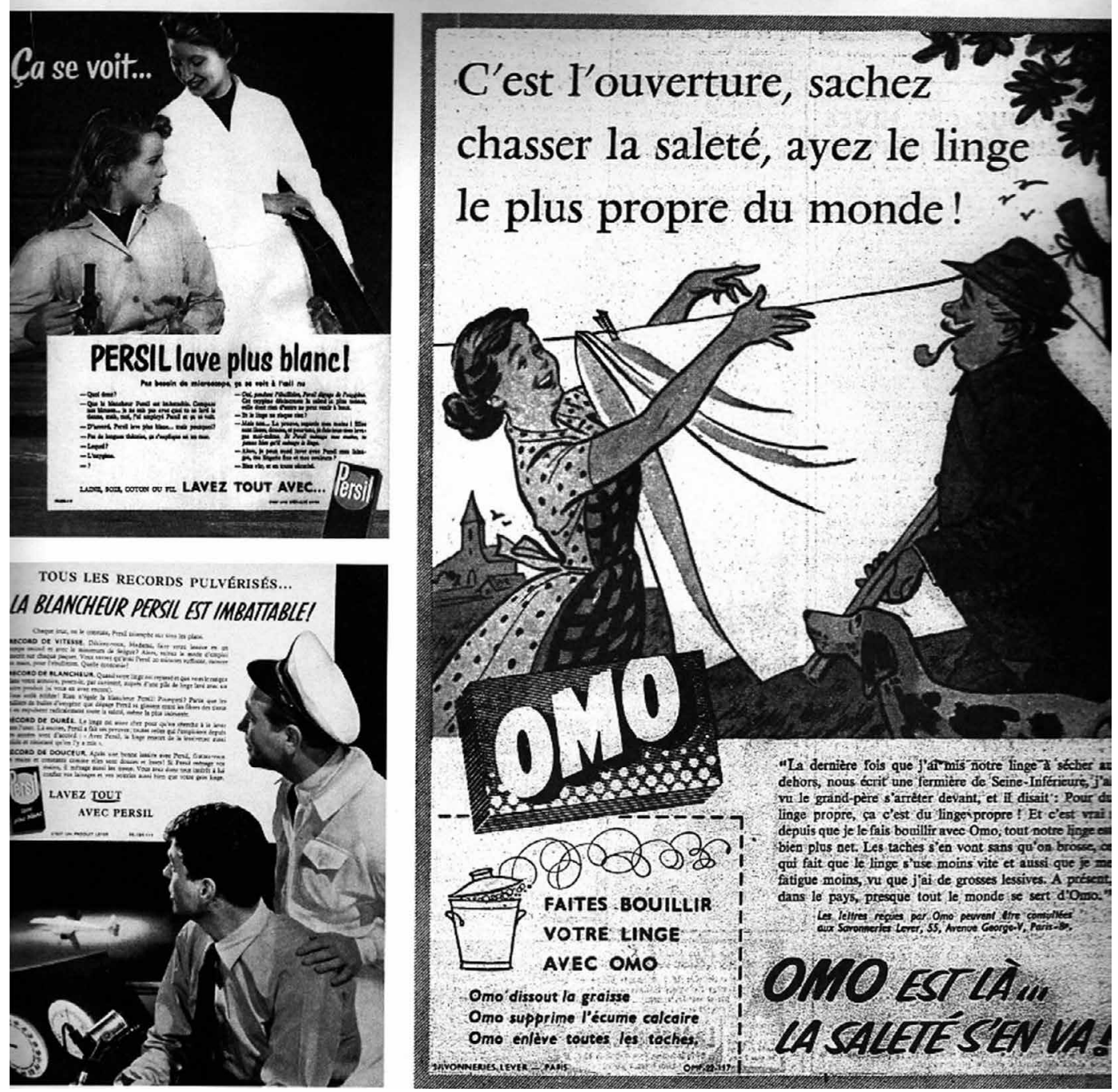

Fonte: Barthes (2010, p. 37). 
O olhar do leitor, involuntariamente, é capturado desta vez pela ilustração maior. Trata-se de um projeto gráfico emoldurado, no qual estão distribuídos os protagonistas do texto. Dividindo-se esse plano de expressão em três terços, tem-se, na parte superior, formada por dois terços, uma superfície verbo-visual que se organiza também em três sequências.

No alto, uma frase, apresentada em três linhas (versos?) espaçadas, próximas da estrutura de uma estrofe, que apresenta um jogo sonoro entre as palavras (sachez, chasser, saleté, ayez, l'ouverture, linge) e que termina por um ponto de exclamação: C'est l'ouverture, sachez / chasser la saleté, ayez le linge/le plus propre du monde! [É a abertura, saiba caçar/expulsar a sujeira, tenha a roupa mais limpa do mundo]. A tradução em português (aqui apresentada apenas para efeito das funções assumidas por um artigo acadêmico) não dá conta das especificidades estilísticas da frase francesa. Caso fosse feita uma tradução para uma peça publicitária, certamente essa exigiria um projeto de fala, no plano verbal, que contemplasse, na língua de chegada, elementos formais de aproximação do texto publicitário/texto poético. Aspectos estritamente formais que não descartam a função consumo, centralizada pela publicidade, e nem sua transformação nas funções sociais constitutivas do texto poético. Garantem, entretanto, um difuso e premeditado posicionamento do destinatário, do interlocutor, num entre-espaço que parece ofuscar a função social da venda.
Trata-se de uma frase imperativa exclamativa, enunciada por um sujeito aparentemente indefinido, que se apresenta como a voz de um saber coletivo, que fala à dona de casa (consumidora), sem mencioná-la nominalmente, mas individualizando-a verbalmente por meio do pronome você contido na forma imperativa do verbo. Além do jogo sonoro e da direção recebida como individualizadora, embora coletiva, a sequência é $a$ abertura (C'est l'ouverture) assume uma bivocalidade importante nos discursos aí veiculados: a abertura tanto pode ser compreendida em seu sentido concreto, ligado ao manuseio da caixa do sabão em pó objeto da publicidade, como abertura enquanto qualidade do espírito: abertura da mente. Essa bivocalidade do termo atinge o leitor/ouvinte/consumidor de duas maneiras fundamentais para a publicidade: (i) no plano banal, corriqueiro, da lavagem da roupa, no qual a abertura da caixa significa a posse do produto e sua utilização; (ii) num plano mais profundo, menos banal, mais existencial, ou seja, em sua condição de ser humano aberto às novidades, ao novo mundo que o cerca. Os verbos no imperativo (saiba, tenha), que constituem um uso clássico do texto publicitário, complementam e reiteram essa bivocalidade, na medida em que funcionam como convite, sugestão, ainda que no fundo pretendam ser uma ordem a ser cumprida: compre. $\mathrm{O}$ termo chasser/caçar, tem, em francês, o sentido de perseguir, podendo, também, significar empurrar para fora, tirar a 
força, desalojar, expulsar. Esse sentido, como se verá mais adiante, não está apenas reiterado no desenho do simpático caçador, mas será um dos pontos essenciais da análise dos mitos construídos em relação ao sabão em pó da marca Omo, como demonstra Barthes no ensaio.

A frase, na verdade, é parte do desenho formado por um cenário bucólico, pairando no ar, integrada ao espaço aberto, ao céu que completa um possível quintal ao ar livre. Além da frase que introduz e explica a cena como um todo, há outros protagonistas: uma mulher jovem e sorridente, portando um avental (símbolo da dona de casa) e que praticamente envolve com seus braços um lençol branco pendurado num varal amarrado no que restou do tronco de uma árvore. $\mathrm{O}$ olhar da jovem dona de casa dirige-se a um senhor de mais idade, que também a olha sorridente, provavelmente um caçador, portando cachimbo na boca, uma arma de caça nas mãos e acompanhado por um cachorro perdigueiro. Ao fundo, vê-se o esboço de uma igreja e de uma casa. No céu, a roupa branca destaca-se esvoaçante, integrada ao cenário. Vários traços desse cenário reiteram os dizeres da frase: abertura da caixa e da mente, concretizada no espaço aberto e na atitude da dona de casa; caçar, concretizado como designação visual do fazer do protagonista. A ideia de diferentes gerações, que se encontram no espaço da nova forma de lavagem da roupa, reitera ao menos duas ideias que fundam o projeto de dizer: abertura de espírito e processo (não apenas produto) de caçar e de expulsar a sujeira, tendo como consequência a roupa mais limpa do mundo (e não somente desse espaço quase rural). A dimensão do expulsar também é explorada por Roland Barthes como um dos componentes do mito representado pelos dizeres da marca Omo, enquanto diferencial em relação a outra marca, que é Persil.

Abaixo desse desenho, ocupando o terceiro texto do conjunto, estão três sequências. À esquerda, uma sequência verbo-visual demarcada por traços interrompidos contendo o desenho de uma espécie de balde com a tampa aberta, que deixa ver a espuma e, um traço estilizado, que pode ser o vapor; duas sequências verbais: na primeira, novamente uma fala imperativa dirigida à consumidora: Faites bouillir/votre LINGE/AVEC OMO [FERVA/FAÇA ESPUMAR/BORBULHAR SUA ROUPA COM OMO]; na segunda, três frases que tem como sujeito o sabão em pó e detergente Omo e suas qualidades: $\mathrm{Omo}$ dissout la graisse/Omo suprimme l'écume calcairel Omo enlève toutes les taches. [Omo dissolve a gordura/Omo suprime a espuma calcária/Omo tira todas as manchas]. À esquerda, embaixo, está a assinatura do produtor: Savonneries Lever - Paris.

Essa sequência é bastante produtiva do ponto de vista discursivo, na medida em que remete à ideia de bouillir/fever a roupa, etapa indispensável até então para tirar manchas. Entretanto, outro discurso assume o lugar do antigo, do 
tradicional. O desenho não mostra uma vasilha sobre o fogo, fervendo roupas. Ao contrário, a ideia de ferver, levar ao fogo, parece substituída em função de uma das qualidades do sabão em pó, ou seja, sua possibilidade de "fazer bolhas", produzir espuma ativa, sem ir ao fogo. A substituição é bastante sutil e eficiente, pois sem descartar a função cumprida pelo processo de ferver, o mesmo termo vai indicar fazer espuma sem ferver. $\mathrm{O}$ termo espuma apresentado pelo desenho, presente no dizer publicitário sobre o sabão em pó Omo, será objeto de análise do ensaio de Barthes, como um dos elementos mistificadores do produto, como um apelo ao luxo, ao glamour, ao toque agradável e sedutor.

Outra sequência verbal, colocada entre aspas à direita, faz parte desse conjunto do terceiro terço. Os créditos esclarecem de imediato tratar-se de uma carta enviada por uma consumidora. Para confirmação, nesses mesmos créditos está incluído o endereço para consultar outras cartas que, como essa, são recebidas pela empresa produtora do sabão. O testemunho da carta da consumidora veicula o discurso da credibilidade do produto e, além disso, serve de legenda ao desenho, explicando-o. Essa narrativa publicitária espontânea, do ponto de vista enunciativo, embora tenha aspas apenas no início e no fim, envolve três enunciadores que desempenham funções diferentes nessa sequência, no funcionamento do todo do texto e nos discursos que são mobilizados. Para caracterizá-la como missivista e fazendeira, é a voz do fabricante que aparece, em discurso indireto, em primeira pessoa do plural e no presente, intercalado na fala da consumidora: "a última vez que coloquei nossa roupa para secar ao ar livre, nos escreve uma fazendeira de Seine Inferieur, eu vi ...". Portanto, há, aí, duas vozes, às quais se soma a do avô, representando não apenas a surpresa diante da brancura do lençol que balança ao vento, mas a sabedoria de uma geração mais velha. $\mathrm{E}$ para responder a esse espanto, a missivista declara todas as qualidades do produto, nomeando e mostrando que as manchas saem sem que haja necessidade de esfregar, apenas mergulhando na espuma de Omo, reiterando sua condição de substituto da "fervura", garantindo trabalho menos cansativo. A consumidora testemunha, ainda, o uso do produto no país todo e não apenas no campo, no interior.

$\mathrm{Na}$ verdade, a missivista, primeira voz da carta, motivo das aspas que indicam a citação da fala de alguém, em discurso direto, é também, e ao mesmo tempo, a quem o projeto de dizer do texto publicitário como um todo se dirige. A voz da consumidora é apresentada como personalizada, individualizada, situada em seu domínio familiar e afetivo, desempenhando sua função de dona de casa, como se vê no desenho para o qual essa carta serve, por assim dizer, de legenda. Ela não está apenas em seu quintal, mas junto com o avô e com o verdadeiro protagonista que vai atrair a atenção de todos 
e motivar a publicidade: a roupa branca, sem sujeira, a mais branca do mundo.

Finaliza essa sequência mais uma frase em que o sabão em pó é o sujeito qualificado, apresentada novamente com traços de enunciado "poético", com rima, ritmo, repetição, reticências: $O m o$ est là...La saleté s'em va! [Omo chega... A sujeira sai!].

Há ainda outro aspecto fundamental para a organização sintática dessa sequência como um todo, de sua condição de enunciado publicitário. É ele que confere coesão às sequências e coerência ao todo verbo-visual. Trata-se do desenho estilizado da caixa do sabão com a marca em fonte grande, colocada transversalmente, de maneira a estabelecer a ligação entre as primeiras duas sequências, ou seja, a que ocupa os primeiros dois terços do todo, e a segunda, organizada no terceiro terço. Sobressaindo-se, tomando praticamente toda a caixa, a marca se deixa ver, em primeiro plano, em perspectiva, sobre traços de bico de pena que formam a caixa e pequenas bolas estriadas brancas, que tanto podem representar o pó como a bolha do sabão, dois elementos constituintes da definição do produto.

Para completar a ilustração, dois outros anúncios, ambos da marca Persil, foram justapostos a esse anúncio de Omo. São fotografias às quais estão acopladas sequências verbais. Na primeira (1955), em um fundo negro, projeta-se no alto à esquerda uma frase em caracteres brancos, terminada por reticências: Ça se voit... [Isto se vê...]. Essa frase introduz o enunciado publicitário, reitera e explica o olhar recíproco dirigido pelas duas mulheres da foto a seus jalecos brancos, mas de tonalidades diferentes. Se reconhece, no contexto, um ambiente de trabalho e não mais doméstico, como no anúncio de Omo. A mulher que está em pé, em maior destaque, tem o jaleco com tonalidade bem mais branca que a outra, que está sentada junto a um microscópio. Há ainda uma espécie de grande etiqueta branca, com textos verbais contendo o bordão Persil lave plus blanc! [Persil lava mais branco!], seguido de uma afirmação relacionada a uma das fotografadas: Pas besoin de microscope, ça se voit a l'oeil nu [Não há necessidade de microscópio, isso se vê a olho nu].

Repartido em duas colunas que completam a foto, há um diálogo argumentativo entre as protagonistas que, num jogo de perguntas e respostas, vai afirmando e destacando as qualidades do produto. O meio utilizado é a comparação entre o branco das duas roupas, ressaltando a diferença entre um produto em relação a outro: brancura imbatível, lavagem mais branca, liberação de oxigênio que retira a sujeira persistente que nenhum outro pode tirar, não estraga mãos, nem as roupas mais finas. $\mathrm{E}$ termina com a frase Lavez tout avec... [Lave tudo com...] complementada pela foto do produto que invade a moldura da etiqueta branca, na qual se encontra o texto verbal, estabelecendo a ligação entre o fundo negro e o branco do suporte do texto. Em letras 
bem menores, aparece o complemento das reticências: ...c'est une spécialité Léver [...é uma especialidade Lever]. A organização sintática reitera a ideia de que o produto e a ação falam por si, no jogo verbo-visual e, ainda, traz a assinatura da marca Lever. Fica evidente a polêmica entre marcas de sabão em pó. Entre produtos que dominavam o mercado naquele momento.

$\mathrm{Na}$ segunda coluna, que temporalmente é anterior à primeira (1954), aparecem dois homens e o enquadramento destaca as camisas brancas que eles usam. Como na anterior, há uma etiqueta sobre o fundo negro que apresenta as qualidades do produto e que, de certa forma, está invadida pelas cabeças dos homens da foto, ligando-se, pela tonalidade do fundo claro, portanto visualmente, ao usuário da camisa mais branca. Nesse texto verbal, há duas afirmações: TOUS LES RECORDS PULVÉRISÉS...[Todos os records pulverizados] e abaixo, em letras maiores, uma segunda afirmação: LA BLANCHEUR PERSIL EST IMBATTABLE! [A brancura Persil é imbatível!]. Aqui, como no anúncio anterior, está instalada, de imediato a polêmica velada com outro produto.

A essas afirmações segue-se um intertítulo, uma afirmação verbal: Chaque jour, on le constate, Persil triomphe sur tous plans [Cada dia, constata-se, Persil triunfa em todos os sentidos]. É uma frase que dá continuidade ao confronto velado de marcas, que responde a outros produtos. A partir daí, um enunciador vai dialogar com a consumidora presumida, demonstrando cada um dos recordes de Persil em relação às roupas: rapidez, brancura, durabilidade, maciez. E o texto termina com a frase imperativa Lavez tout avec Persil [Lave tudo com Persil], colocado ao lado da caixa que reitera a marca. A exemplo do anúncio anterior, aparece a assinatura do fabricante.

Apenas como curiosidade, o leitor brasileiro deve ter lembrado da imagem desses dois produtos no Brasil, mais ou menos na mesma época. Um deles Persil, que se denominava Rinso, e deixou durante anos um bordão que corria de boca em boca, extrapolando a esfera publicitária: "brancura rinso", ou seja, rinso como adjetivo de branco, significando "muito branco". Pela força, passou a referir-se não apenas às roupas lavadas com esse produto, mas à qualidade do branco. Podia qualificar, por exemplo, uma pessoa de pele muito branca. Esse jogo entre as características diferenciadas entre os dois produtos será motivo da análise de Roland Barthes em seu ensaio, chamando a atenção, ao final, para um dado que se constata aqui: a encenação das duas marcas não impede que se saiba, do ponto de vista da análise, tratar-se de produtos vindo da mesma multinacional.

Se a memória do leitor de Barthes não alcança o tempo desses anúncios, sites que contam a história da publicidade brasileira podem ser consultados. Deixo, então, dois exemplos em que muitos dos discursos que circulam na publicidade francesa estão presentes na publicida- 
de brasileira. Confiro, ainda, ao leitor o prazer de reconhecer as formas e os discursos dirigidos à mulher, à dona de casa, à mãe de família, dentre outros aspectos para os quais o texto de Barthes, recuperado a seguir, alerta para mitos presentes naqueles momentos e modernizados nos dias atuais.

Figura 2 - Sequência 2

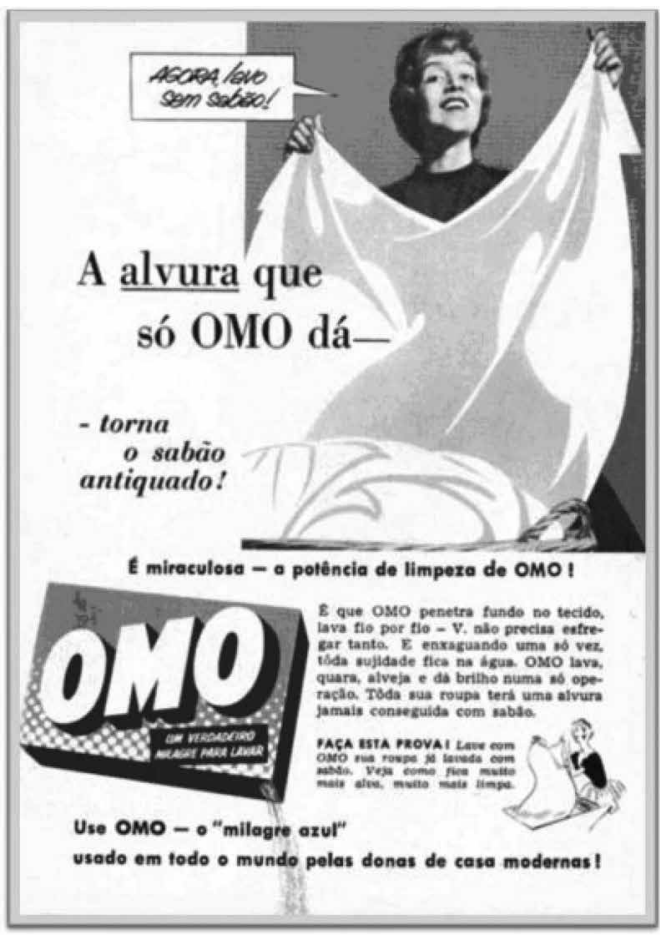

Fonte: Mundo das Marcas (2006a).
Figura 3 - Sequência 3

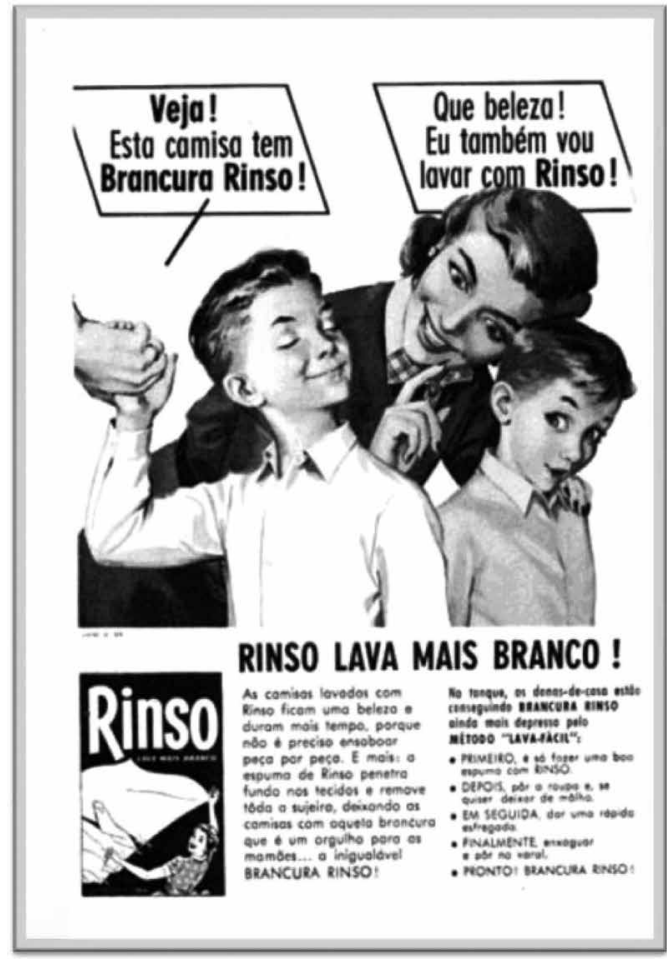

Fonte: Mundo das Marcas (2006b).

\section{Algumas considerações finais sobre mitologias verbo-visualizadas no passado e no presente}

$\mathrm{Na}$ introdução ao livro Mitologias, Roland Barthes explica que, ao tentar refletir a respeito dos mitos da vida cotidiana francesa, tomou como ponto de partida acontecimentos daquele momento, os quais eram veiculados pela imprensa, cotidiana ou semanal, ou ligados à vida artística: "um artigo de jornal, uma fotografia de semanário, um 
filme, um espetáculo, uma exposição" (1972, p. 7). A explicitação em detalhes do que $o$ autor entende por mito aparece na segunda parte dessa mesma obra, sob o título $O$ mito, hoje (p. 131-178), abrangendo vários aspectos, inclusive a ideia de que o mito era visto como um sistema semiológico:

[...] "o mito é uma fala" [...]. Naturalmente, não uma fala qualquer. São necessárias condições especiais para que a linguagem se transforme em mito [...] ele é um modo de significação, uma forma. Será necessário, mais tarde impor a esta forma limites históricos, condições de funcionamento, reinvestir nela a sociedade: isso não impede que seja necessário, de início, descrevê-la como um a forma. $\mathrm{O}$ mito não se define pelo objeto de sua mensagem, mas pela maneira como a profere [...]. Essa fala é uma mensagem. Pode, portanto, não ser oral; pode ser formada por escritas ou por representações: o discurso escrito, assim como a fotografia, o cinema, a reportagem, o esporte, os espetáculos, a publicidade, tudo isso pode servir de suporte à fala mítica (p. 131-132).

Os textos reunidos nessa segunda parte, cujo objetivo é apresentar a concepção de mito, podem ser considerados como o resultado teórico das leituras feitas por Barthes ao longo da obra, conforme se observa em Saponáceos e Detergentes, aqui escolhido para discussão. Nesse trabalho especificamente, o autor faz uma análise das características da publicidade de determinadas marcas de sabão em pó e de detergentes na França dos anos de 1950, fundado em sua ideia de mito enquanto linguagem, enquanto discurso. Ele não focaliza uma peça de publicidade em particular, mas os efeitos de sentido que o conjunto das peças referentes a essas marcas provocam nos consumidores, caso de Omo, Javel [Água Sanitária], Persil [Rinso], Crio, Paic, algumas das quais conhecidas pelos brasileiros. Para tanto, extrai, da forma como o produto é falado pelas diversas marcas, sentidos, articulações de sentidos e efeitos de sentido que são recebidos e assumidos, pelos consumidores, pela sociedade em geral, como verdadeiros, reais, naturais, indiscutíveis.

Começa o ensaio referindo-se ao primeiro congresso Mundial de Detergência, realizado em Paris em setembro de 1954, que "deu azo a que o mundo se abandonasse à euforia do Omo" (Barthes, 1972, p. 29). Segundo ele, a partir de então, consagrou-se a ideia, ancorada na publicidade maciça de detergentes, que não somente eles não eram nocivos, apesar de sua fórmula química agressiva, mas que na verdade podiam até causar benefícios. Para demonstrar a dimensão dessa fala mítica, distorcida e aderente, apresenta as relações dicotômicas existentes entre "remédio e mal", "produto e sujeira", eixos que colocavam os líquidos purificadores de um lado, caso da água sanitária, e os detergentes de outro.

Como os constituintes químicos não poderiam ser mudados em benefício da saúde do consumidor, e muito menos sua ação, sob pena de eles deixarem de ser produtos eficazes para a limpeza, a mudança se dá no plano da linguagem. Pela força do discurso, o alvo das ações abrasivas, perigosas, deixa de ser a 
roupa, a mão de quem utiliza o produto e passa ser a sujeira. A água sanitária assume sua função "matar a sujeira" e o detergente "expulsar a sujeira", como afirma o autor:

[...] os cloros e os amoníacos são sem dúvida nenhuma os delegados de uma espécie de fogo total, salvador, mas cego; os pós são, pelo contrário, seletivos, empurram, conduzem a sujeira através da trama do objeto, desempenham uma função de polícia, não de guerra (BARTHES, 1972, p. 29).

Ao estabelecer essa diferença, o autor traça um curioso paralelo com a etnografia, explicitando esses dois aspectos presentes na publicidade e sua relação com o consumidor, com aquele que utiliza os produtos, dizendo que

[...] o líquido químico prolonga o gesto da lavadeira batendo a roupa, e os pós constituem a dona de casa comprimindo e torcendo a roupa ao longo do lavadouro (BARTHES, 1972, p. 29).

Nessa leitura que toca aspectos impensáveis para a natureza dos produtos de limpeza, mas que de fato foram criados pela publicidade e tornaram-se mitos poderosos, o autor faz ainda mais uma distinção entre o que denomina publicidade psicológica e publicidade psicanalítica de sabão em pó. Essa distinção que toca duas dimensões humanas importantes, as quais motivaram duas formas de conhecimento ligadas a desejos, sentimentos, imaginário - Psicologia e Psicanálise -, ajuda a entender as diferenças publicitárias entre Persil e Omo, presentes na ilustração da edição de 2010 e em muitos outros anúncios aludidos neste artigo, cujo traço domi- nante é a brancura. A brancura Persil, segundo Barthes,

[...] fundamenta o seu prestígio na evidência de um resultado; apela-se para a vaidade, para o amor das aparências, apresentando e comparando dois objetos, um mais branco do que o outro (BARTHES, 1972, p. 30).

Omo, por sua vez, mesmo indicando o efeito do produto, acentua o processo de sua ação: permite que o consumidor torne-se "cúmplice de uma liberação e não usufrua apenas de um resultado" (BARTHES, 1972, p. 30). O leitor pode constatar essa dimensão na ilustração presente na edição de 2010, por exemplo, e também nas duas publicidades brasileiras desses produtos escolhidas dentre tantas outras existentes, aqui escolhidas para serem citadas e confrontadas com as francesas.

A consequência desse discurso publicitário é que a matéria adquire, segundo o autor, estados-valores. Destacando os termos profundo e espumoso, associados ao sabão Omo, observa que a roupa adquire profundidade, dimensão que lhe confere um estatuto jamais imaginado e que a magnifica, dando-lhe a característica de objeto sedutor, ligando-o a carícias. A espuma, por sua vez, é traduzida por ele como luxo:

[...] em primeiro lugar, aparenta uma certa inutilidade; depois, a sua proliferação abundante [...] predispõe o consumidor a uma imaginação aérea da matéria, a um modo de contato simultaneamente ligeiro e vertical, desejado e deliciosamente gozado [...] pode mesmo ser signo de uma certa espiritualidade (BARTHES, 1972, p. 30). 
Tudo isso, entretanto, tem uma finalidade muito clara que é "mascarar a função abrasiva do detergente sob a imagem deliciosa, simultaneamente profunda e aérea". Barthes termina o texto, conforme mencionado acima, com um toque profundamente significativo, lembrando que as diferenças entre as duas marcas não apagam o fato de que ambas pertencem a um mesmo produtor, a uma mesma multinacional.

Diante da edição de 2010, a descrição/ leitura da ilustração do ensaio Saponáceos e Detergentes traz para o leitor de hoje um passado em que os projetos gráficos da publicidade de marcas de sabão encenam discursos ligados à vida do trabalho caseiro, do lar, espaço social em que a mulher é a figura dominante. Há, também, o espaço do trabalho externo, urbano, em que o anúncio pode ser protagonizado tanto por homens como por mulheres e, independentemente do ambiente, o sujeito é a nova maneira de agir desses produtos de limpeza de roupas. $\mathrm{O}$ texto de Barthes, que apesar da densidade analítica é bastante curto, ocupando duas páginas na edição brasileira e uma na edição de 2010, levanta aspectos que dizem respeito à forma profunda como esses modos de dizer o produto atingem zonas psicológicas, psicanalíticas do consumidor, atuando sobre suas crenças, suas vaidades, seus desejos, sua posição no mundo. Invertendo miticamente as funções abrasivas e cotidianas do sabão, a publicidade o instaura como salvador de roupas, de tempo da dona de casa, acariciador de mãos e de vaidades, sedutor, muito próximo do humano.

A leitura dos dois textos separadamente é possível e ambas são profundamente produtivas. Tanto que o texto verbal já era conhecido e a ilustração pode ser lida mesmo sem a presença do ensaio. Entretanto, a leitura do conjunto sem dúvida produz efeitos de sentido diferentes das leituras excludentes. Ler hoje publicidades dos anos 1950 evoca um passado, num sentido quase romântico, não fosse o fato de, sob essa aparente ingenuidade, promover mitos que se renovam sob as mesmas condições de produção da publicidade, mas que continuam apelando para as crenças e desejos criados pela sociedade, pela força do consumo.

Para confirmar esse aspecto duradouro e essencial à publicidade, isto é, construir formas de dizer o produto que atinjam zonas do consumidor que vão muito além do espaço externo da lavagem das roupas, é possível saltar no tempo e aportar numa das últimas campanhas de um dos produtos focalizados por Barthes e que ainda se mantém como marca muito vendida, desejada pelo consumidor. Trata-se da campanha publicitária "Eu te OMO", que juntou as marcas Omo e Brastemp, como pode ser conferido no site http://www.youtube. com/watch?v=C9zqr4l2YRg. Criada pela agência Etna, é a "primeira na qual a Whirlpool e Unilever atuam juntas, celebrando o 'casamento' das marcas Brastemp e OMO”, conforme se lê nas 
explicações contidas no site http://www. agenciaetna.com.br/ETNA/?p=3526, constando a data de 25/09/2013.

Em uma das peças publicitárias, que pode ser ouvida e vista em Omo Multiação. Amigas.mp4, acontece a cena descrita a seguir. Dentro de uma lavanderia muito bem organizada, uma mulher, de quem não se vê o rosto, guarda algo numa prateleira e, ao virar-se para sair, deixa ver, muito rapidamente, a embalagem de OMO líquido e mais uma caixa azul. Com um fundo musical, a câmera aproxima-se de duas máquinas, uma de lavar e uma de secar, enquanto se ouve um diálogo característico de duas jovens amigas:

- Ai, sabe quando alguém te completa?

- Ih...tá apaixonada, é?

- Ooooh, mas ele é uma graça...

- E ele não quer que eu trabalhe tanto, sempre me ajuda mesmo com as manchas difíceis.

- É mesmo?

- Ai, eu tô parecendo uma boba?

- Ah tá demais.

- Ih acho que eu tô amando...

- Xi, fala baixo, menina, que ele está por perto, não vai dar bandeira.

- Pouca prática...

Há momentos, pelo efeito da animação, em que a declaração ouvida é acompanhada, bem de perto, das bocas das máquinas que se mexem, falando. No final desse diálogo, a câmera vai subindo e foca uma prateleira à direita, a mesma em que a jovem mulher deixou uma peça de roupa, a embalagem de Omo líquido, vista rapidamente no início do anúncio. Essa embalagem ganha o primeiro plano, repercutindo suas cores fortes, com predomínio do azul. Ao mesmo tempo, uma bolha de sabão em forma de coração flutua no ar, ao lado da embalagem. Ela vai subindo e estoura como se fosse a resposta amorosa do sabão à declaração de amor da máquina. Ao mesmo tempo, uma voz em off diz:

Omo. Imbatível com as manchas mais difíceis, até no ciclo rápido.

Recomendado pelo maior fabricante de lavadoras do Brasil.

Enquanto a voz diz isso, o espectador pode ver/ler, no alto à direita, num círculo de fundo branco:

Omo. Recomendado pelo maior fabricante de lavadoras do Brasil, separado por um traço do e-mail euteomo.com.br e da logomarca Brastemp.

Nessa campanha, pelo jogo fonético, pela troca de um único som, uma única letra, cria-se um bordão - Eu te OMO -. Trata-se de um trocadilho com a expressão Eu te amo, uma forma mundial de expressar amor, proximidade física, afetiva, atração, química perfeita. No lançamento da campanha, dois atores que acabavam de protagonizar uma novela de televisão, referem-se à expressão como substituta a antiga declaração de amor. O processo parece querer aproximar-se da força do bordão da marca da lavadora que, para dizer que um produto ou indivíduo é bom, mas não é o melhor, afirma: não é uma Brastemp... 
O que se observa é que as qualidades do produto, ressaltadas nos anúncios analisados por Barthes, continuam presentes, formuladas por projetos de dizer que tocam o imaginário do consumidor, espelhando os mitos da contemporaneidade. Brancura não é, hoje, uma palavra neutra do ponto de vista dos discursos politicamente corretos. O mesmo vai acontecer com a imagem da mulher, com os discursos relacionados ao feminino. Por essa razão, outros discursos devem dizer os produtos. E é no avanço da tecnologia, sinônimo de atualidade, marca do presente, que os discursos vão ser buscados. Isso transparece tanto no filme, no que se refere à animação, como na substituição do trabalho humano pelo trabalho das máquinas e dos detergentes que a elas se associam.

Se essas máquinas substituem, com perfeição, o homem justamente num dos aspectos definidores de sua condição humana, ou seja, o trabalho, isso pode significar que elas têm potencial para adquirir outras qualidades humanas. No caso, o amor. E é aí que reside a função maior concentrada na simples substituição de uma vogal do verbo amar, no presente do indicativo, amo, coincidindo com a marca omo. A consequência enunciativa é que omo, enquanto verbo, implica um sujeito de verbo de estado. Esse trocadilho, amo/omo, apesar da obviedade, apresenta-se como um lance de criatividade, descoberta do óbvio, em termos de jogo de palavras, que diz muito a respeito das crenças da modernidade, das relações homem/máquina.
O filme que simula a declaração de amor entre máquina e sabão esclarece, do ponto de vista industrial/comercial, que quanto maior a automatização, o desempenho das máquinas de lavar, maior é o consumo de detergente, constatação óbvia que leva à associação de duas grandes marcas. Assim, os verdadeiros atores não são mais as donas de casa, as pessoas, o ser humano. Esses são os consumidores que convivem, muito proximamente, com máquinas, as quais substituem vários trabalhos e transformam formas de lazer. No espaço da casa habitado pelas máquinas, pelos detergentes e pelas roupas limpas e sujas, que é a lavanderia, as pessoas saem de cena, como nesse filme/anúncio. Dão lugar às máquinas. Essas máquinas associam-se a produtos, casam-se com eles, uma vez que, na realidade, sua venda é de dependência recíproca. Mas essa realidade organiza-se num projeto de dizer em que, pelo humor e pelos recursos tecnológicos, máquina e sabão assumem a condição de sujeitos do discurso amoroso. E o amor, ironicamente, é transformado numa graciosa bolha de sabão.

\section{Revisiting mythologies through dialogic lenses}

\section{Abstract}

Mythologies, Roland Barthes's collection of essays, published in France in 1957 and translated into Portuguese in 1972, aimed to carry out a double task: ideological criticism of 
the so-called mass culture and semiological dismantling of this language. Although his object of analysis was predominantly visuality and verbal-visuality (photographs, advertising, the press, etc.), the essays were not accompanied by illustrations. Half a century later, Jacqueline Guittard reissued the book, illustrating it with images of his time. This reissue was entitled Mythologies ilustrées. It is comprised of original essays and more than 120 illustrations which allow the current reader to see the images used by the author to show, with wit and irony, the mythological operation of recurring themes in the society of that time. This article aims to discuss the possibility of reading verbal-visuality from the dialogical discourse theory proposed by Bakhtin and the Circle, using the essay "Detergents e soap products" in Mythologies ilustrées as the object of analysis. From Barthes's analyses, one has the verbal perspective. In order to analyze visuality, another author joined in to present images not necessarily found in Barthes's archive, but retrieved from his objects of analysis, which were circulating at that time. As this article deals with the reading of society and their beliefs from an advertisement, it also intends to verify, by means of semiological dismantling, if/and which myths found in it are either resistant to contemporary reading or lost in time.

Keywords: Contemporary mythologies. Roland Barthes. Advertising. Verbal-visuality. Dialogical discourse analysis.

\section{Notas}

1 Original: "proposer au lecteur le document authentique, c'est à dire celui que Roland Barthes avait sous ses yeux ou qu'il gardait en mémoire, et, s'il ne s'en trouvait pas, de s'en tenir à ceux qu'il aurait pu voir au moment où il rédigeait ses chroniques".

2 Original: "Ce ne sont donc pas des illustrations barthésiennes à proporement parler que l'on trouvera en regard de ces chroniques, mais plus simplement celles du temps, choisies au plus près de l'écriture mithologique et des événements".

3 Para o aprofundamento do estudo dos conceitos de texto e discurso em Bakhtin e o Círculo, consultar: Brait (2012, p. 9-29).

4 Para maior esclarecimento do que se entende hoje por Análise Dialógica do Discurso (ADD), tendência dos estudos da linguagem desenvolvida, especialmente no Brasil a partir dos trabalhos de Bakhtin e do Círculo, consultar: Brait (2012, p. 9-31).

5 Para o aprofundamento da concepção e leitura análise do verbo-visual, consultar: Brait (2013).

\section{Referências}

BAKHTIN, Mikhail. O problema do texto na linguística, na filologia e em outras ciências humanas. In: Estética da criação verbal. 4. ed. Tradução de Paulo Bezerra. São Paulo: Martins Fontes, 2003. p. 307-335.

BAKHTIN, Mikhail. Problemas da poética de Dostoiéviski. 4. ed. Trad. de Paulo Bezerra. São Paulo: Forense Universitária, 2008.

BARTHES, Roland. Mythologies ilustrées. Par Jacqueline Guittard. Paris: Seuil, 2010.

BARTHES, Roland. Saponáceos e detergentes. In: Mitologias. Trad. de Rita Buongermino e Pedro de Souza. São Paulo: Difusão Europeia do Livro, 1972. p. 29-30.

BRAIT, Beth. Olhar e ler: verbo-visualidade em perspectiva dialógica. Bakhtiniana, São Paulo, v. 8, n. 2, p. 43-66, jul./dez. 2013. 
BRAIT, Beth. Perspectiva dialógica. In: BRAIT, Beth; SOUZA-e-SILVA, M.C. (Orgs.). Texto ou discurso? São Paulo: Contexto, 2012. p. 9-29.

BRAIT, Beth; SOUZA-e-SILVA, M.C. (Orgs.). Texto ou discurso? São Paulo: Contexto, 2012.

BRAIT, Beth. Análise e teoria do discurso. In:__ (Org.). Bakhtin: outros conceitos-chave. 2. ed. São Paulo: Contexto, 2012. p. 9-31.

CAMPANHA Eu te OMO. Disponível e m : < http://www.youtube.com / watch?v=C9zqr4l2YRg $>$. Acesso em: 13 jan. 2014.

MUNDO DAS MARCAS. 2006a. Disponível em: <http://www.mundodasmarcas.blogspot. com/2006/05/omo-lava-mais-branco.html>. Acesso em: 13 jan. 2014.

MUNDO DAS MARCAS. 2006b. Disponível em: <www.mundodasmarcas.blogspot. com/2006/05/omo-lava-mais-branco.html>. Acesso em: 13 jan. 2014.

OMO em constante atualização. Disponível em: <http://www.unilever.com.br/Images/ Omo_tcm95-106348.pdf>. Acesso em: 13 jan. 2014 . 